\title{
VIBRATIONS CAUSED BY TRAIN PASSAGES IN UNDERGROUND TUNNEL COMPARED TO VIBRATIONS FROM GROUND SURFACE TRANSPORTATION - SOME RESULTS OF INVESTIGATIONS
}

\author{
KRZYSZTOF STYPUŁA ${ }^{1}$
}

\begin{abstract}
The paper describes experimental investigations of vibrations caused by train passages in the shallow underground tunnel (in Warsaw, Poland) in comparison to the results of measurements of vibrations from ground surface transportation (trams and buses). Propagation of surface ground vibrations from underground tunnel is presented. The problem of dynamic response of a building and influence of vibrations caused by underground on people residing in a building is discussed as well. The dynamic response of the building to underground vibrations is essentially different from the response of a building excited by surface sources of transport vibrations. Also the distribution of influence of the transport vibrations on people in the building is significantly different in both cases.
\end{abstract}

Keywords: underground vibrations, transport vibrations, ground vibrations, building vibrations

\section{INTRODUCTION}

The results described were obtained from experimental investigations which for some years have been carried out in Warsaw subway $[1,2]$. Investigations concerns the influence of vibrations caused by underground train passages in the tunnel on the neighboring buildings and on people staying in them - see Figure 1.

The need for such a study results from the fact that the Warsaw underground runs in shallow underground tunnels (the depth of the underground track is from 9.0 to $10.5 \mathrm{~m}$ counting from the head of the rail). Taking into consideration the influence of vibrations on people in the buildings, the adopted range of the dynamic influences was $40 \mathrm{~m}$.

During the investigations, the vibrations from an underground tunnel were compared with vibrations excited by the ground traffic (trams, buses etc.), and in this way significant differences were found in the propagation of vibrations in the ground and the reaction of the buildings and residents on vibrations.

\footnotetext{
1 Cracow University of Technology, Dept. of Civil Engineering, Institute of Structural Mechanics
} 


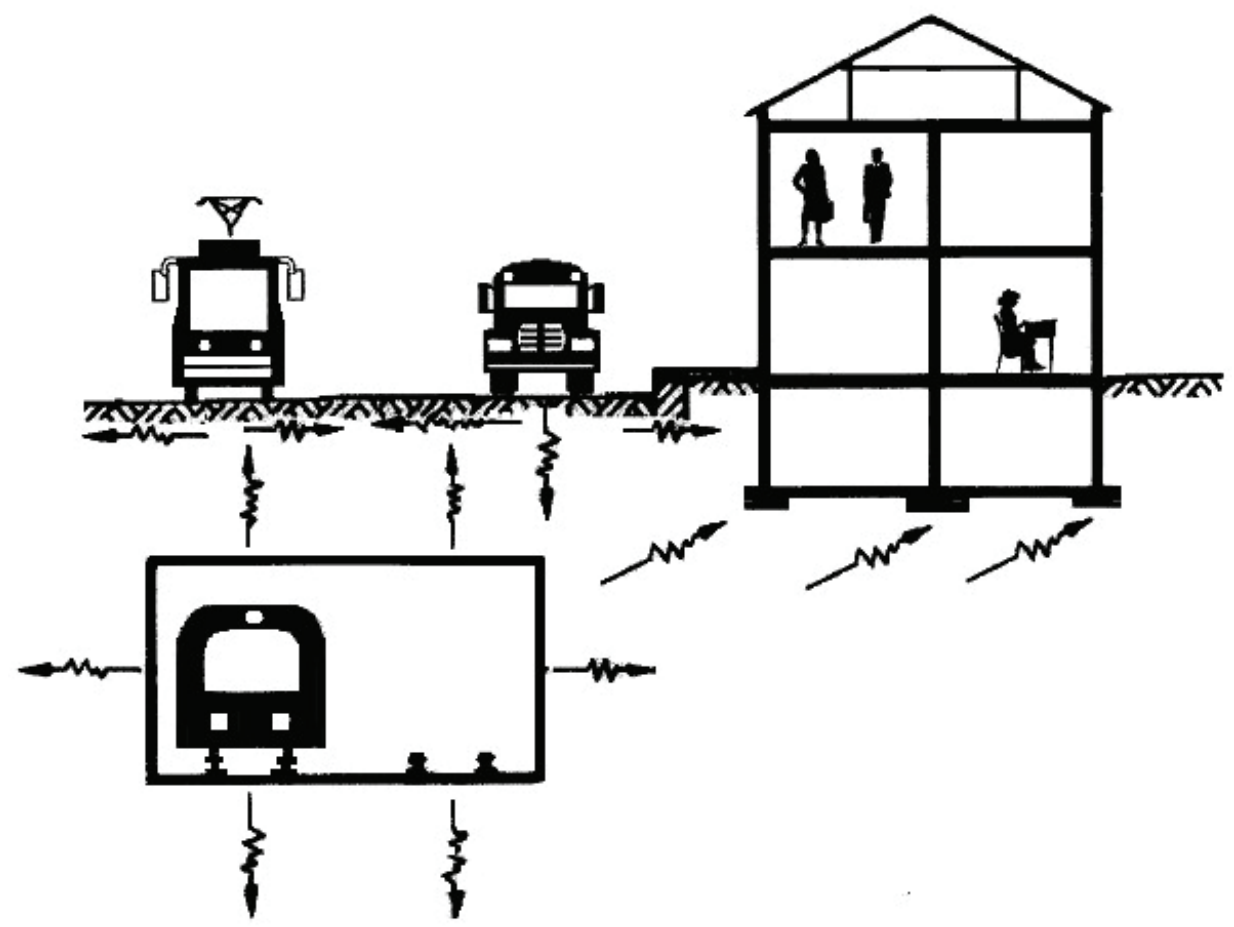

Fig. 1. Transmission of waves generated in a underground tunnel and caused by the surface transport to the building

\section{Propagation of surface vibrations in the ground}

In the case of the surface sources of harmonic vibrations or similar, the propagation of Rayleigh waves in the surface part of the ground is often described by the formula:

$$
A_{r}=A_{0} \sqrt{\frac{r_{0}}{r}} \exp \left[-\alpha\left(r-r_{0}\right)\right]
$$

where $\mathrm{A}_{0}$ and $\mathrm{A}_{\mathrm{r}}$ are respectively amplitudes of surface ground vibrations at distances $\mathrm{r}_{0}$ and $\mathrm{r}$ from the vibration source, and $\alpha$ is defined as the coefficient of absorption. The above formula is confirmed by the experimental investigations [3, 4]. It describes a monotonic decrease of vibration amplitudes along with the increasing distance from the source of vibration. Because propagation curves of vibrations from the surface traffic have similar nature (see Figure 2) if the ground is homogeneous (not shallow stratified), the formula (1) is often used in this case [5]. 


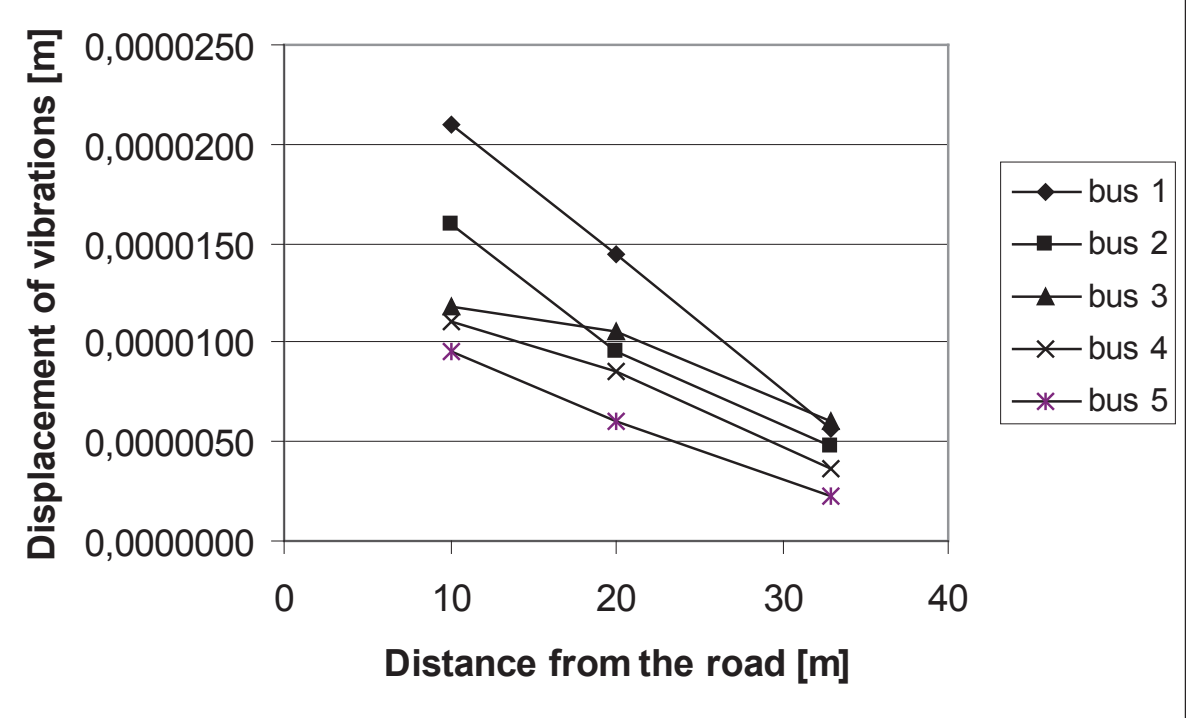

Fig. 2. Dependence of maximum amplitudes of the radial component $x$ (horizontal component in the direction perpendicular to the road) of the ground vibration displacements caused by buses crossing from the distance from the road [5]

As far as the transport vibrations from surface sources are concerned, difficulties in describing the phenomenon of the vibration propagation refer only to stratified ground (because of the interference of waves reaching directly to the ground surface and the waves reflected from the boundary layers of the ground - see Figure 3). Therefore, in the case of the shallow underground vibration sources (to which underground belongs) they always occur, and the ground stratification can additionally complicate process of propagation. These result from the process of interference of waves reaching the ground surface which occurs independently whether the ground is stratified or not. Body waves emitted from the vibration source (located in the ground) reach particular surface points at different angles. If the angle of wave incidence is appropriately small, the wave is totally reflected. If the angle of body wave incidence increases, the waves undergo partly reflection and partly deflection. The deflected wave propagates along the ground surface as a surface wave and undergoes interference with the components of body waves reaching the ground surface directly as shown in Figure 4. Of course, it concerns larger number of waves, since both longitudinal and transverse waves undergo reflection and deflection. Moreover, each of the waves reaches particular points of the ground surface at another time moment - depending on the depth of the vibration source, distance of the reception point of vibrations from their source (r) and the characteristics of the ground: modulus of linear deformation, Poisson's ratio and mass density. 


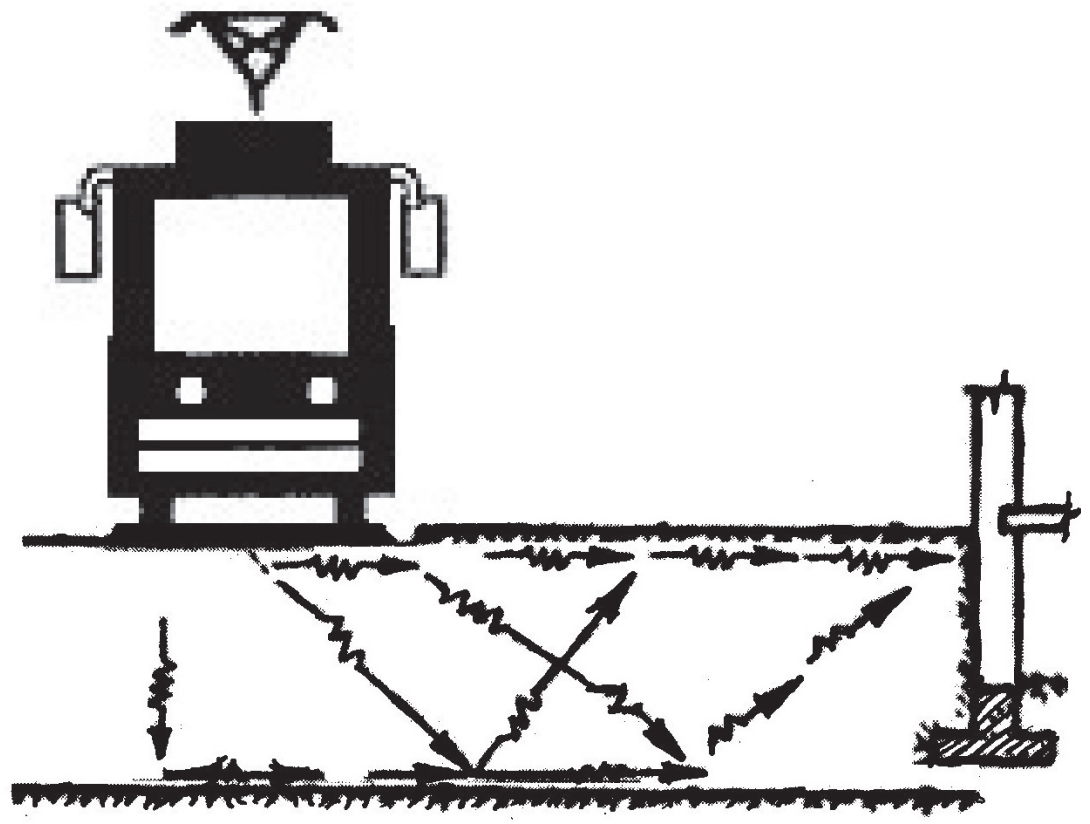

Fig. 3. Scheme of propagation in layered ground of waves caused by the surface source of the transport vibrations

Because of these phenomena, a unique picture of the propagation of vibration is obtained as shown by the results of measurements presented below.

Figgure 5 shows the results of investigation carried out by Czernobaj and Szatkowskij [6]. It concerns the surface ground vibrations excited by a vibrator situated inside the underground tunnel. These results, in the form of the relation of amplitudes of surface vibration of ground A (at distance from 0 to $40 \mathrm{~m}$ ) and amplitudes of forces $\mathrm{A}_{0}$, include vertical vibrations (continuous line) and horizontal ones (broken line). Particular curves marked with numbers in Figure. 5 correspond to the following conditions:

1 - structure of the underground tunnel made with precast reinforced concrete, excitation frequency $35 \mathrm{~Hz}$,

2 - structure of the tunnel as above, excitation frequency $70 \mathrm{~Hz}$,

3 - structure of the tunnel made of the monolithic reinforced concrete, excitation frequency $43 \mathrm{~Hz}$.

Amplitudes increase to a certain distance from the tunnel axis and then start to decrease. This is the result of the above mentioned interference of waves and formation of Rayleigh waves (surface waves) at a certain distance from the epicenter above the underground vibration source. 




Fig. 4. Scheme of wave propagation from the underground tunnel to the surface of the ground

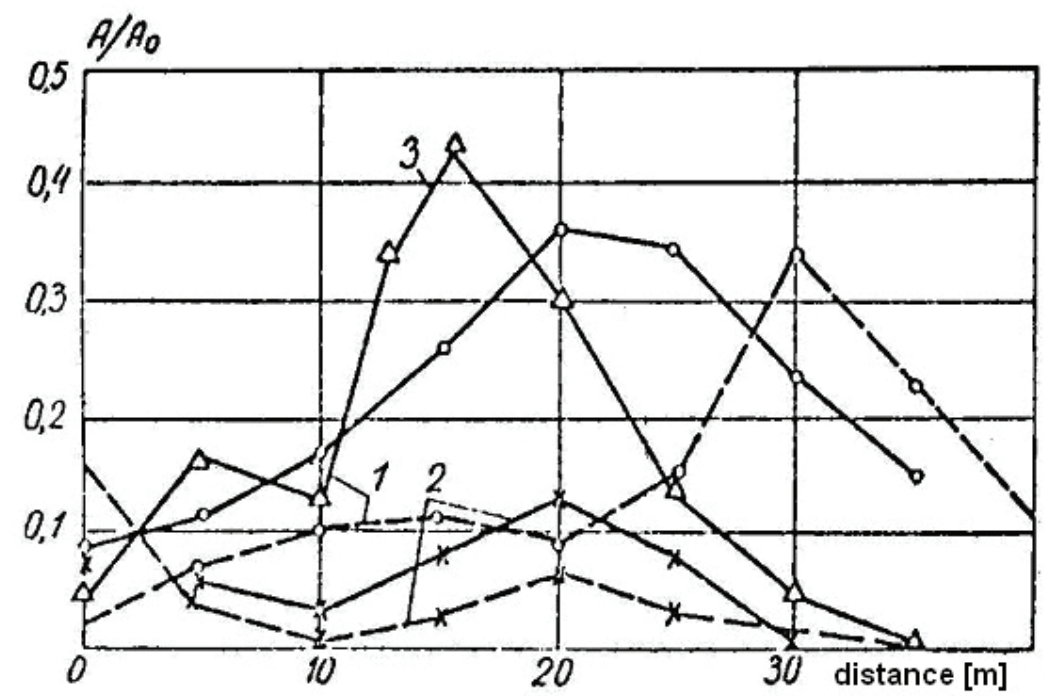

Fig. 5. Distribution of amplitudes of vertical and horizontal vibrations of ground surface by Czernobaj and Szatkowskij [6]: 1 - precast reinforced concrete structure of the tunnel at forcing frequency $\mathrm{f}=35 \mathrm{~Hz}$, 2 - as above at $\mathrm{f}=70 \mathrm{~Hz}, 3$ - for monolithic reinforced concrete structure at $\mathrm{f}=43 \mathrm{~Hz}$ 
Several experimental investigations of distribution of acceleration amplitudes of surface vibrations excited by underground train passages in the tunnel of the shallow underground has been carried out by the author in Prague (Czech Republic) and in Warsaw (Poland). The measurements concerned horizontal radial component x (i.e. the direction perpendicular to the tunnel axis), horizontal transverse component y (i.e. the direction parallel to the tunnel axis), and vertical component $\mathrm{z}$ of acceleration of the surface ground vibrations. The results of investigation are presented below as an example. Figure 6 shows time traces of component $x$ of these accelerations in the distance from 0 to $10 \mathrm{~m}$ from the epicenter above the tunnel (i.e. from the point over the axis of underground track) registered during the passage of one of the underground



Fig. 6. Time-traces of the horizontal radial component $\mathrm{x}$ (in the direction perpendicular to the underground tunnel) of acceleration of the surface ground vibration caused by passage of the train (in underground tunnel) and registered in distances $0,2.5,5.0,7.5 \mathrm{i} 10$ meters from epicenter over the axis of the underground track 
trains. The maximal values of the amplitude of acceleration during 10 passages of the underground trains in the distance from 0 to 25 meters are presented in Figures 7, 8 and 9 , for component $\mathrm{x}, \mathrm{y}$ and $\mathrm{z}$, respectively. The results of investigation show a visible non-monotonic character of changes of vibration amplitude along with distance from the tunnel.

Otherwise it is for the surface sources, in the case of ground vibrations excited by underground operation, local extremes occur as the effect of the mentioned interference of vibrations reaching particular points of the ground surface. For that reason, the forecasting of these vibrations is much more troublesome. It is important for the practice that these difficulties concern also a prognosis of the dynamic influences on newly designed buildings, basing upon results of measurements of the surface ground vibrations excited by underground train passages in the tunnel. As it can be seen, if the reliable kinematics excitation of the designed building is to be established, the measurement of surface vibrations of the ground can not be confined to one or two points.

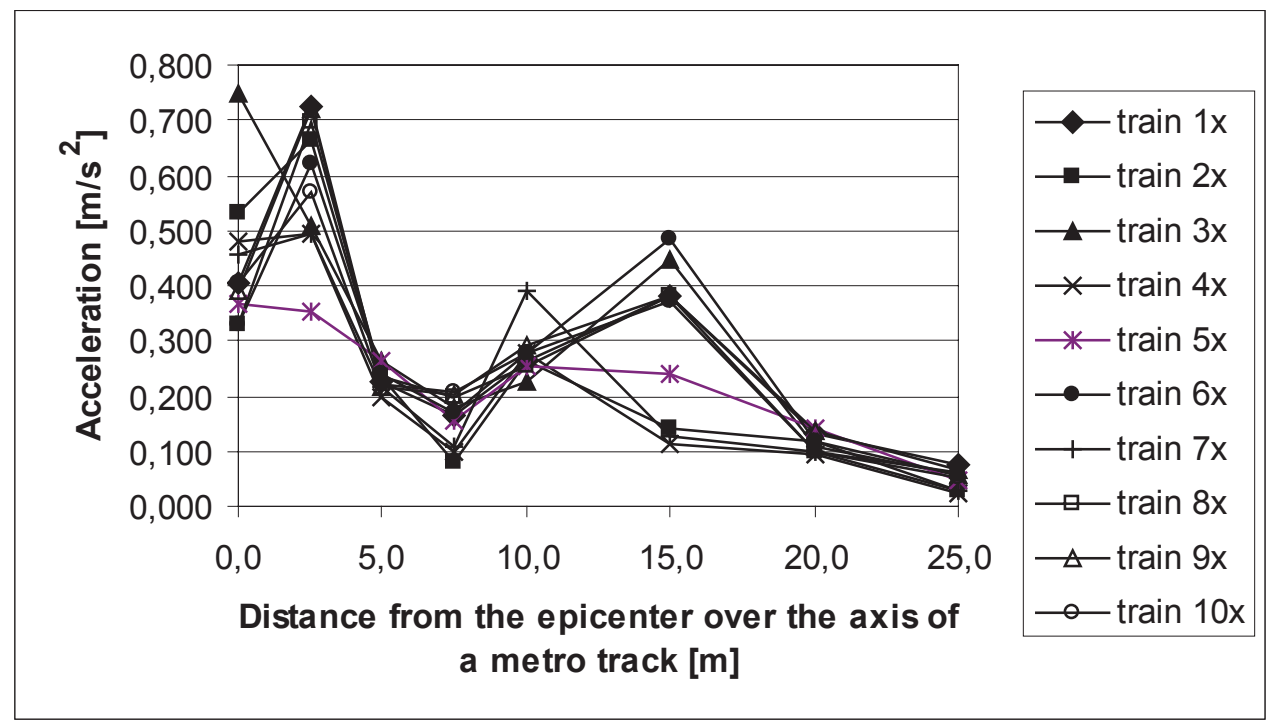

Fig. 7. Propagation of the ground surface vibrations caused by underground train passages in tunnel - distribution of acceleration amplitudes for horizontal radial component $\mathrm{x}$ (direction perpendicular to the underground tunnel) 




Fig. 8. Propagation of the ground surface vibrations caused by underground train passages in tunnel - distribution of acceleration amplitudes for horizontal transverse component y (direction parallel to the underground tunnel)

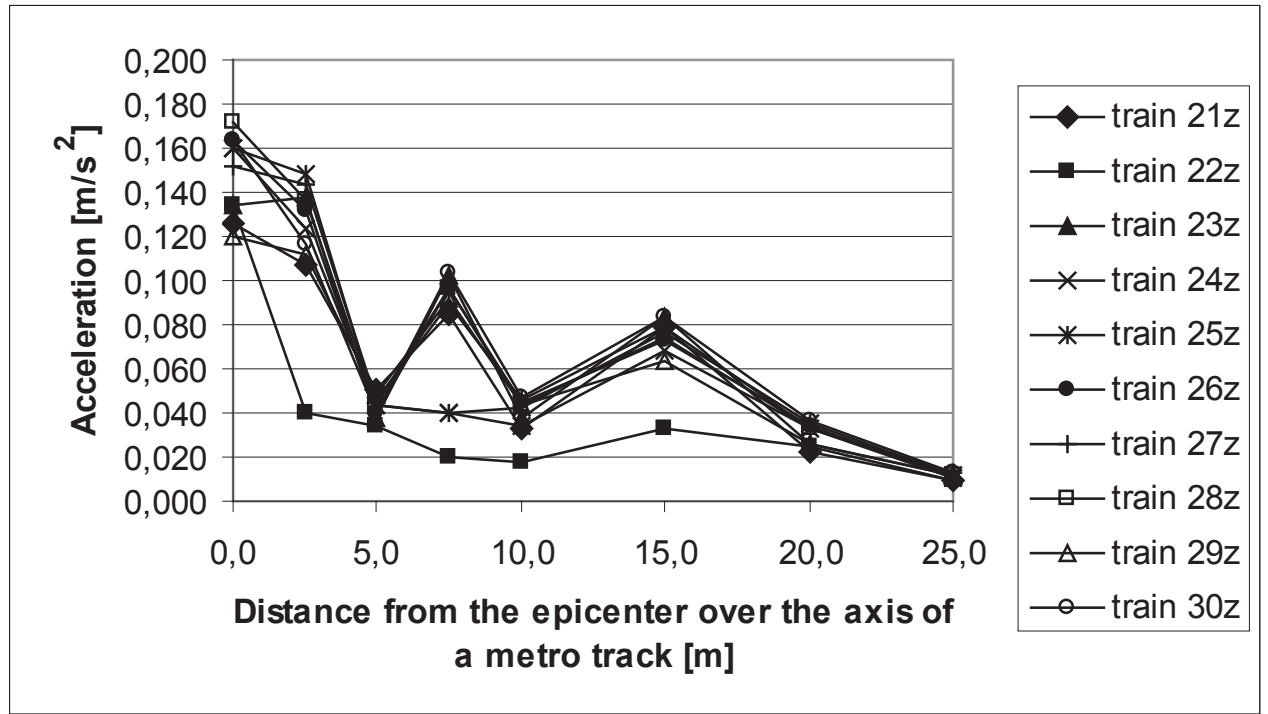

Fig. 9. Propagation of the ground surface vibrations caused by underground train passages in tunnel - distribution of acceleration amplitudes for vertical component $\mathrm{z}$ 
The level of vibrations received from the ground by the building is the result of reduction of vibrations at the interface of the ground with the building foundation, in the process of dynamic interaction of the ground-building. The level of vibrations is not only dependent on the horizontal distance $r$ (Figure 10) from the wall of the tunnel to the building but also on the depth of the top of the tunnel under the ground surface $\mathrm{H}$. It seems that a good parameter for determining of these relationships is the distance $\mathrm{L}$ between the foundation of the building and the tunnel wall. This relationship is shown in Figure 11 (horizontal component of vibrations perpendicular to the axis of the tunnel $\mathrm{x}$ ) and Figure 12 (vertical vibrations component $\mathrm{z}$ ) as an example of vibrations measurements in nine buildings at the depth of the tunnel $\mathrm{H}$ from 5.5 to $6.5 \mathrm{~m}$. The vibrations were measured in the ground level of the buildings.

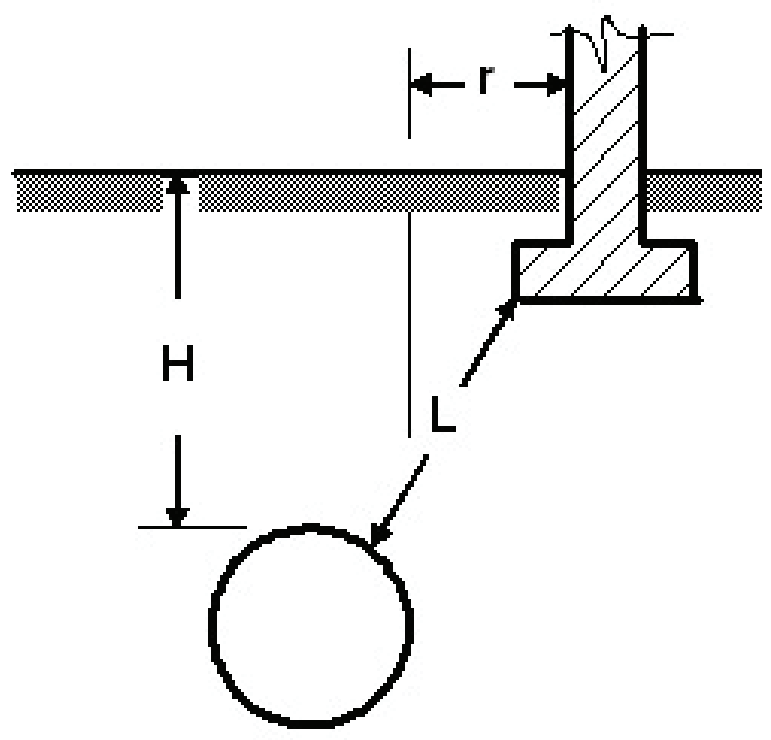

Fig. 10. Scheme of the position of the tunnel relative to the building 


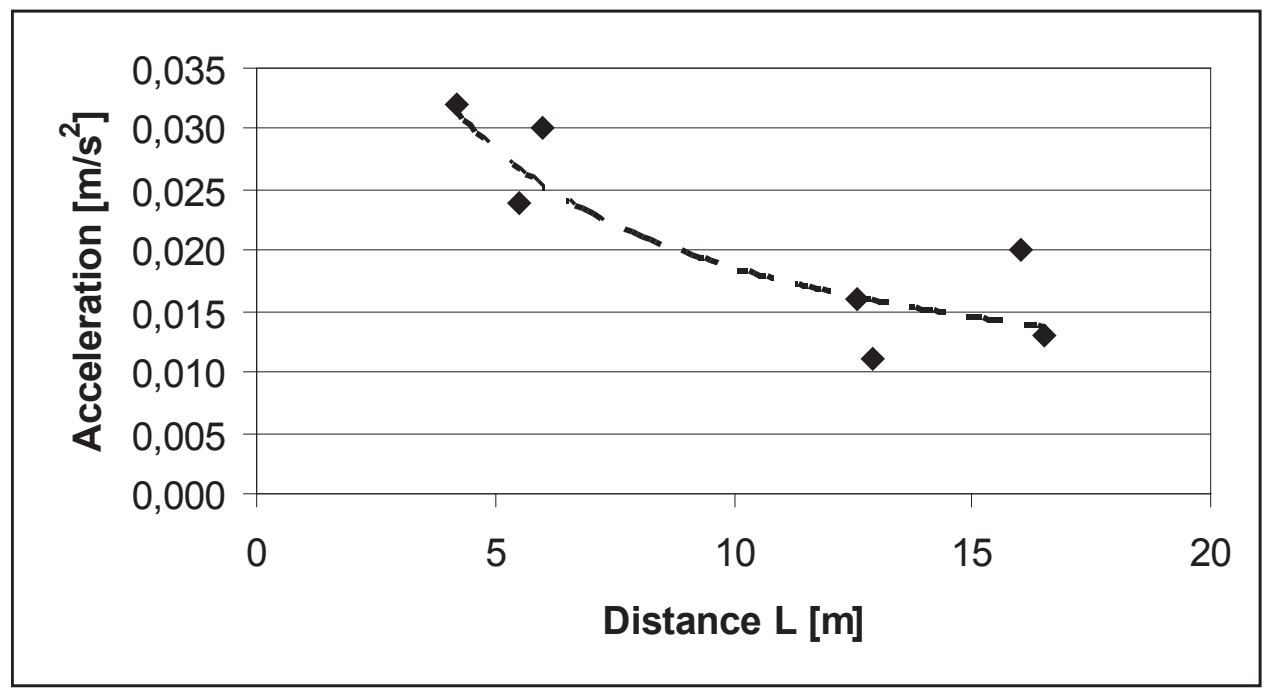

Fig. 11. Vibrations of the building in the ground level - dependence of acceleration amplitudes of horizontal radial component $\mathrm{x}$ (direction perpendicular to the underground tunnel) on the distance of the building foundations from the tunnel walls $\mathrm{L}$

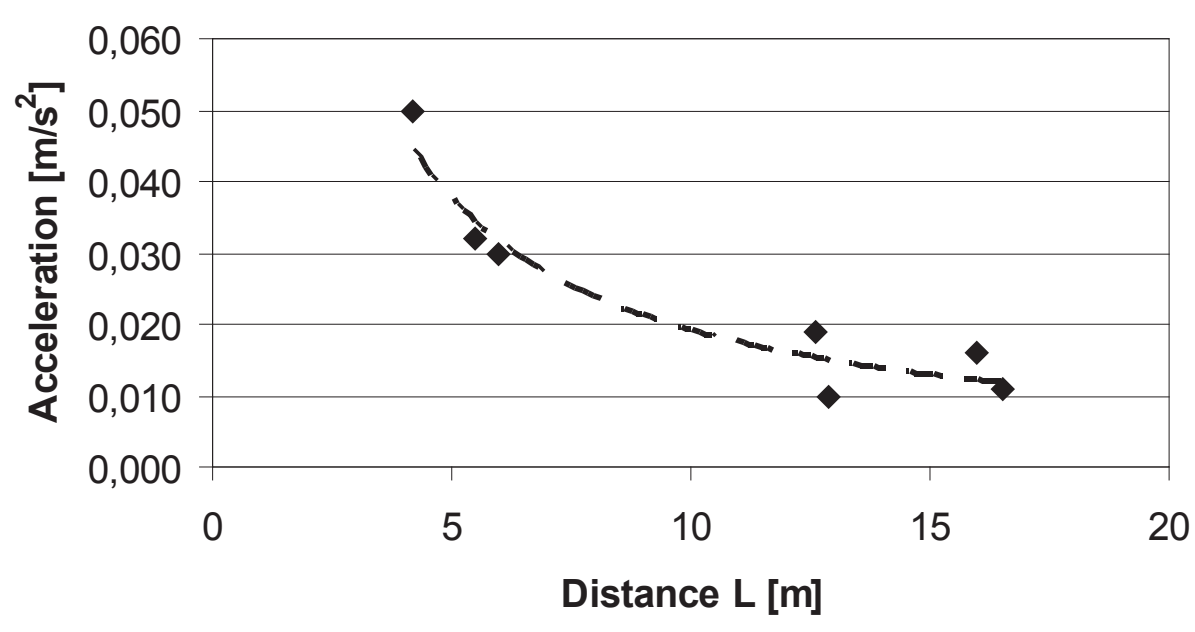

Fig. 12. Vibrations of the building in the ground level - dependence of acceleration amplitudes of vertical component $\mathrm{z}$ on the distance of the building foundations from the tunnel walls $\mathrm{L}$ 
As a result of experimental studies carried out by the author, the following formula for estimation of the maximum amplitude (Amax) may be applied, depending on the location of the tunnel and the building:

$$
A_{2}=A_{1}\left(\frac{L_{1}}{L_{2}}\right)^{n}\left(\frac{H_{1}}{H_{2}}\right)^{m}
$$

where:

$\mathrm{A}_{1}$ - the maximum amplitude (Amax) of vibrations of the building (in the ground level) whose foundation is in the distance $\mathrm{L}_{1}$ from the tunnel, and the depth of the top of the tunnel below the surface of ground is $\mathrm{H}_{1}$,

$\mathrm{A}_{2}$ - the maximum amplitude (Amax) of vibrations of the building (in the ground level), whose foundation is in the distance $\mathrm{L}_{2}$ from the tunnel and the depth of the top of the tunnel below the surface of ground is $\mathrm{H}_{2}$,

$\mathrm{m}, \mathrm{n}$ - factors taking into account the set of vibrations in the ground, on the basis of measurements, among other geometric attenuation and absorption of vibrations.

The above formula may be used to predict the amplitudes of vibrations of buildings on the assumption that $\mathrm{L}_{1}<\mathrm{L}_{2}$ and $\mathrm{r}_{1}<5 \mathrm{H}_{1}$ and $\mathrm{r}_{2}<5 \mathrm{H}_{2}\left(\mathrm{r}_{1}\right.$ and $\mathrm{r}_{2}$ are the distances of buildings from the tunnel walls as measured in the plane view - Figure 10). If these last two conditions are not fulfilled, differences may occur due to the formation of the Rayleigh waves on the surface of the ground.

\section{DyNAMIC RESPONSE OF BUILDINGS}

As referred to surface sources of transport vibrations, the problem of reaction (response) of buildings to these vibrations is, as a matter of fact, recognized. Buildings behave like a supporting structure fixed more or less elastically in the ground, and in their responses to kinematic excitation the lowest (first of all the first) frequencies of free bending vibrations dominate. As a result, amplitude of vibrations increase along with the height of higher level floors, and the building response measured at the level of the top storey shows the highest value. In dynamic calculations (building response, forces of inertia) carried out by loading the structure model with kinematic excitation in form of time traces of vibrations, or considering the response spectrum of the first three frequencies of free bending vibrations of the structure as a whole (neglecting local effects), is in principle.

The carried out dynamic investigations showed that the building reaction to vibrations excited by train passages in the underground tunnel is different from that one described above for the surface sources of vibrations. This is well illustrated in Table 1 by the results of measurements of three buildings subjected to the influences of both kinds of excitation. There are the maximal listed values of acceleration amplitude $\left(\mathrm{a}_{\max }\right)$ 
at the level of the ground floor, and the response at the level of the highest storey of the building, measured during a single passage of a surface transport vehicle (bus or tram), and subsequently during a underground train passage in the underground tunnel. With reference to both types of sources of vibrations, the measurements in a given building were carried out in the same measurement points.

Table 1.

Comparison of values of maximal vibration acceleration amplitudes $\left(\mathrm{a}_{\max }\right)$ recorded during passages surface transport vehicles and metro trains

\begin{tabular}{|c|c|c|c|c|c|c|c|}
\hline \multirow[t]{2}{*}{ Building } & \multirow[t]{2}{*}{ Forcing } & \multicolumn{3}{|c|}{$\begin{array}{c}\text { Acceleration at the level of } \\
\text { the first floor } \\
{\left[\mathrm{m} / \mathrm{s}^{2}\right]}\end{array}$} & \multicolumn{3}{|c|}{$\begin{array}{c}\text { Acceleration at the level of } \\
\text { the highest floor } \\
{\left[\mathrm{m} / \mathrm{s}^{2}\right]}\end{array}$} \\
\hline & & $\mathrm{X}$ & Y & $Z^{*}$ & $\mathrm{X}$ & Y & $Z^{*}$ \\
\hline 1 & 2 & 3 & 4 & 5 & 6 & 7 & 8 \\
\hline \multirow{2}{*}{ A } & bus & 0,003 & 0,003 & 0,007 & 0,004 & 0,004 & 0,018 \\
\hline & metro & 0,032 & 0,015 & 0,042 & 0,004 & 0,006 & 0,025 \\
\hline \multirow{2}{*}{ B } & bus & 0,005 & 0,003 & 0,010 & 0,007 & 0,005 & 0,015 \\
\hline & metro & 0,011 & 0,008 & 0,031 & 0,007 & 0,008 & 0,008 \\
\hline \multirow{2}{*}{$\mathrm{C}$} & tram & 0,003 & 0,002 & 0,010 & 0,006 & 0,005 & 0,014 \\
\hline & metro & 0,009 & 0,006 & 0,020 & 0,004 & 0,004 & 0,008 \\
\hline
\end{tabular}

Unlike the surface excitation, in the case of underground train passages, the highest values of amplitudes of acceleration, both horizontal vibrations of the building, and vertical floor vibrations, occur in the lower part of the building. On the higher one, these values are smaller or similar (in any case, do not grow up). The causes of the different dynamic reaction of buildings to train passages in the underground tunnel, as compared to the excitation by surface transport sources, can be followed at the example of the building B. It was modeled by the use of the finite elements method as was shown in rough outlines in Figure 13. The immersion of the lower building floor in the ground was also considered. 


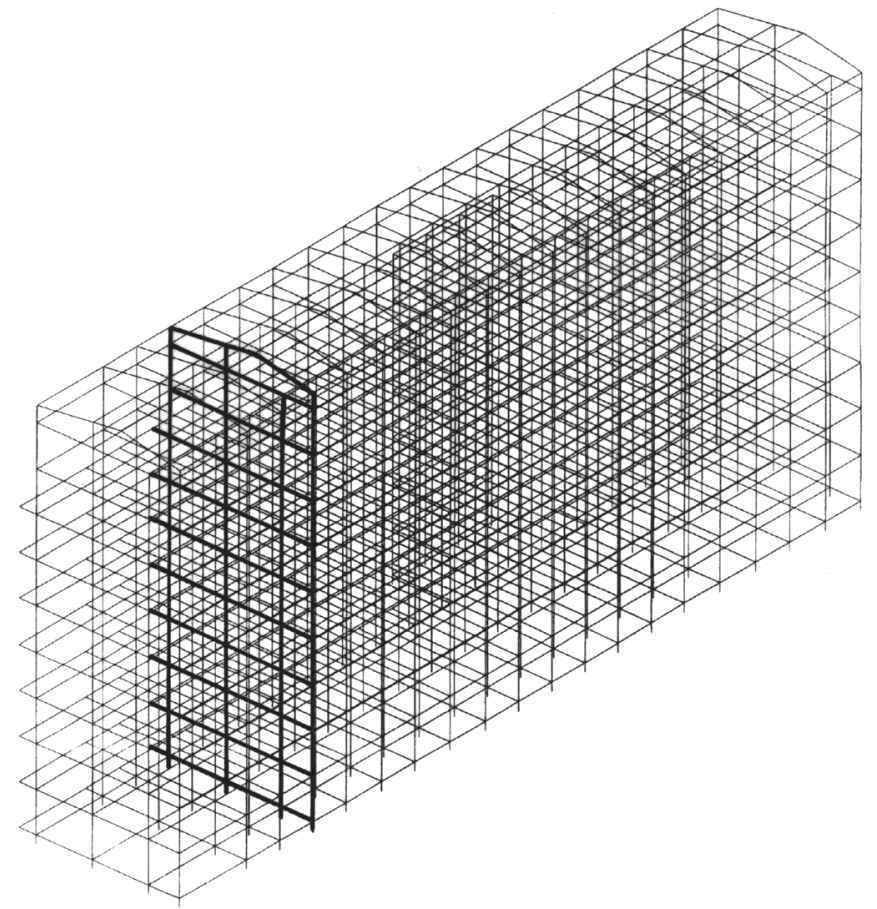

Fig. 13. Computational model of the building B

A full analysis of the integration with respect to time (time history analysis) was carried out for two kinds of kinematic excitation:

- $\quad$ surface source - bus passage,

- underground source - passage of train in the underground tunnel.

In both cases, these were real time traces of excitation recorded on the foundations of the building $\mathrm{B}$, and the results were compared with building responses to these excitation measured also "in situ". The results of the calculation are presented here on the example of one of frames of the building structure (marked with a thicker line in Figure 13) on which both excitation (at the level of the foundation) and response (at the level of the garret floor) were measured.

The calculations considered 100 shapes of free vibrations of the building. The first 7 shapes of bending and bend-torsional vibrations of the whole structure (Figure 14) have the highest participation (not less than $1 \%$ ) in the final response of the building. In the case of excitation due to a bus passage, the participation of particular shapes of vibrations in the total response of the building was respectively: shape I $-94.3 \%$, II $-4.0 \%$, III $-1.0 \%$ and the others less than $1 \%$. Whereas at underground train passage, this participation was: shape I $-7.0 \%$, II $-12.0 \%$, III $-42.0 \%$, IV $-23.0 \%$, V -11.0 $\%$, VI $-3.0 \%$, VII $-1.1 \%$. 


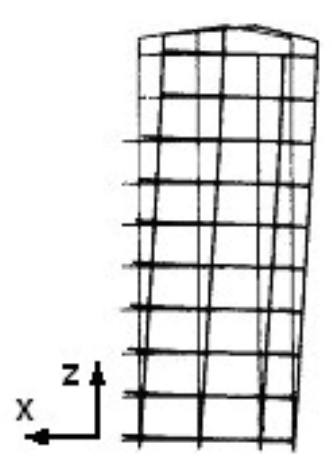

Shape I

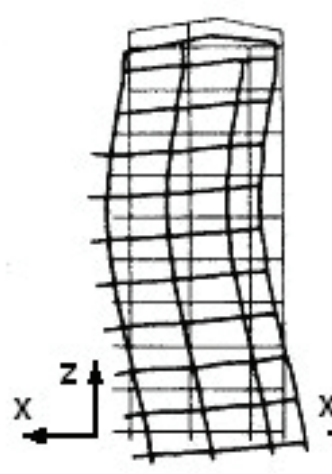

Shape II



Shape III

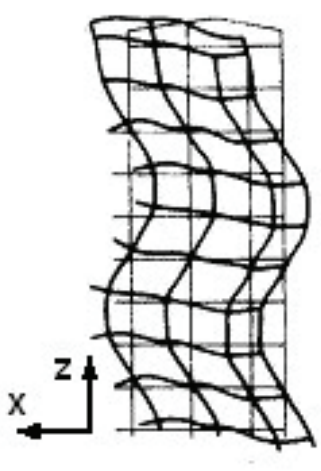

Shape IV


Shape VII

Fig. 14. Vibration shapes of a chosen frame of building B

The distribution of the sum of the absolute acceleration of vibrations with respect to the height for both cases of excitation is shown in Figure 15.

In view of the results of presented investigation, the specific character of paraseismic effects caused by train passages in underground tunnel, differentiating them from the effects of surface sources, should be taken into consideration in their diagnostic evaluation. Therefore, in calculation of the inertia forces, the kinematics excitation in form of time traces obtained from measurements of vibrations of the building foundation (or building vibrations at the level of the ground) should be preferred. It is also possible to make use of the response spectrum made on the basis of these measurements; in such a case it is not enough to consider in calculations only the first three shapes of 
a)

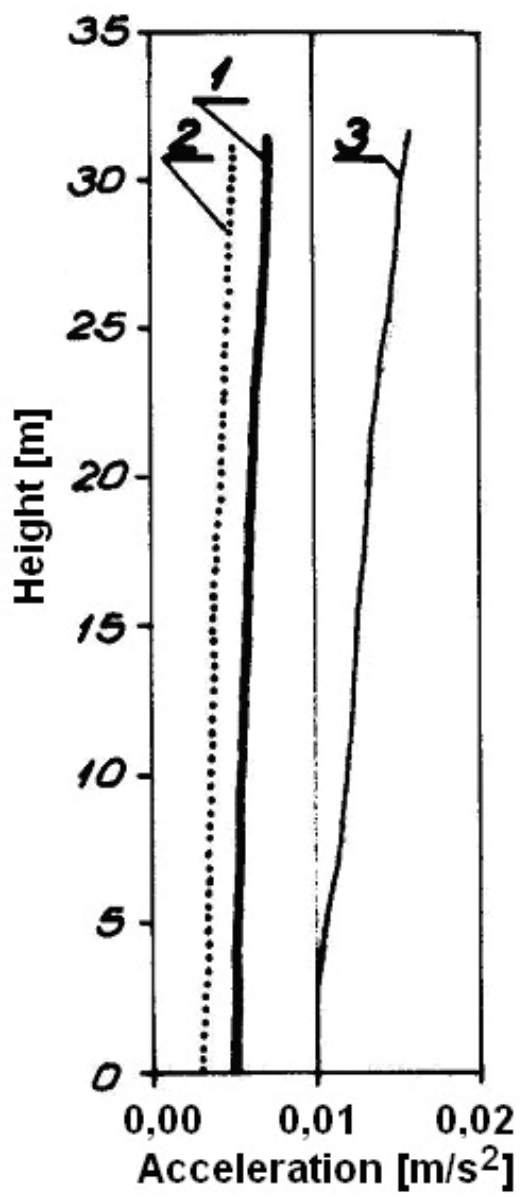

b)

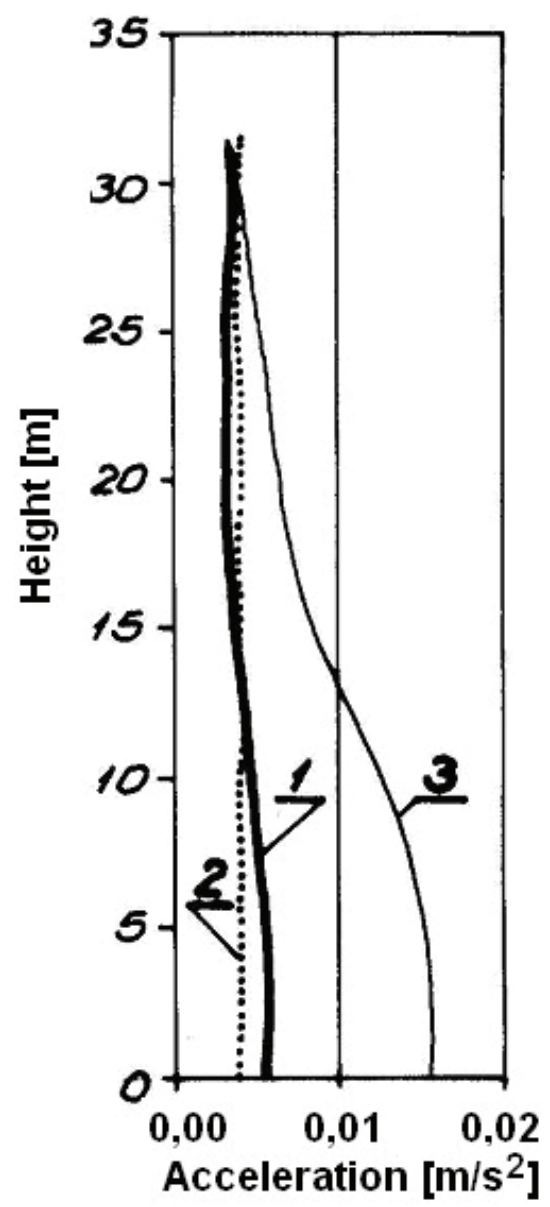

Fig. 15. Distribution of values of absolute acceleration with respect to building height for a) forcing by bus passage and $\mathrm{b}$ ) forcing by underground train passage in the tunnel: 1- horizontal radial component $\mathrm{x}$, 2 - horizontal transverse component y, 3 - vertical component of floor vibration $\mathrm{z}$

free vibrations of the object as a whole, but 10 or more consequent free vibration shapes should be considered. It should be stressed that the question concerns the successive shapes of free vibrations of the structure in global sense. 


\section{INFLUENCE OF VIBRATIONS ON PEOPLE IN BUILDINGS}

Criteria of evaluation of vibration impact on people in the buildings are described in the international standard ISO 2631-2 [7] and also in Polish PN-88/B-02171 [8]. The differences mentioned above also apply to this impact. The influence of vibrations excited by surface transport on humans is the lowest on the first floor level and usually increases with the height of the building. In the case of vibrations caused by underground the influence on people at higher floors is lower or sometimes the same, in comparison with the first floor.

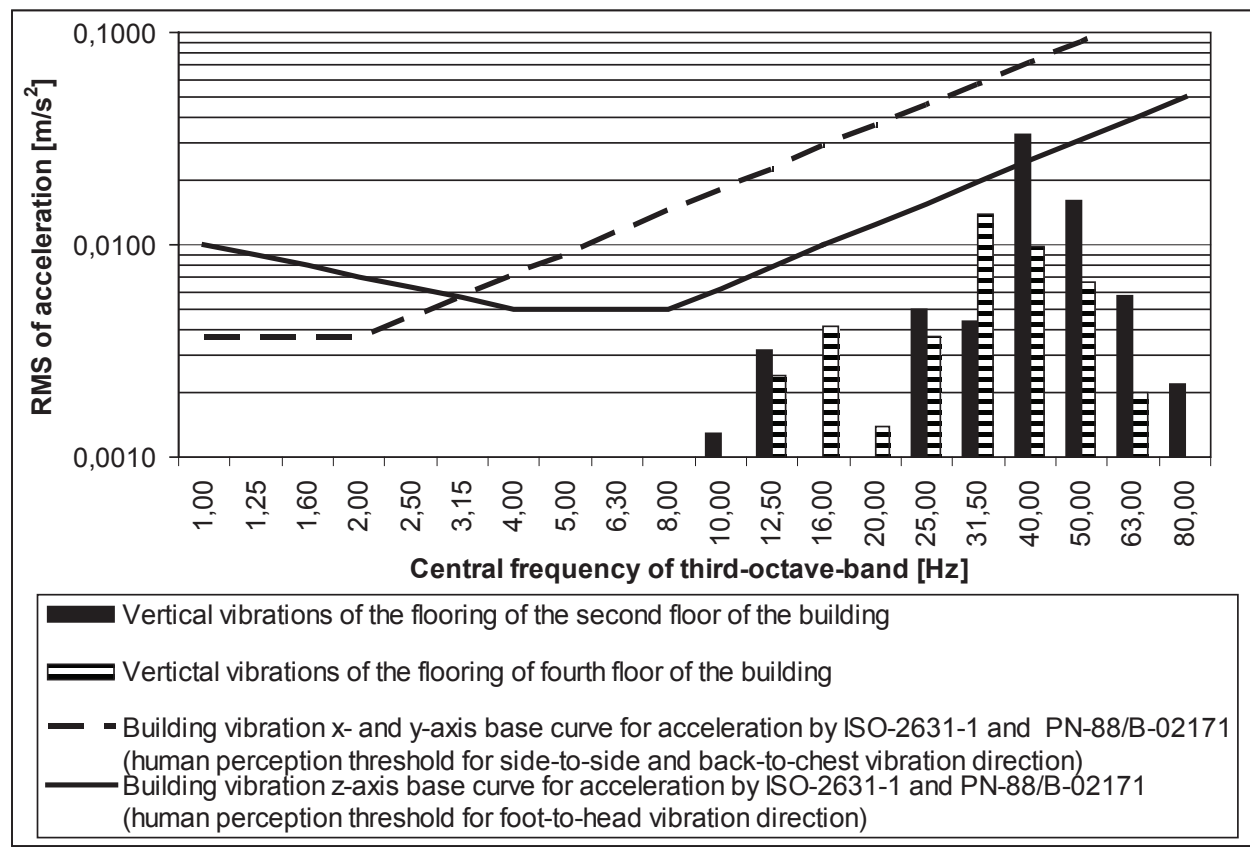

Fig. 16. Results of analyzes of the influence of vertical vibration on people living on the second and the fourth floor of the building I-10 in the case of vibrations caused by underground train passage in a tunnel 25 meters from the building

This problem is illustrated, for example, in the results of measurements carried out in a brick building with four floors and a basement. The building marked I-10 is located in Warsaw and is subjected to vibration caused by tram passages (at a distance $9 \mathrm{~m}$ from the building), and by train passages in the underground tunnel (at a distance of $25 \mathrm{~m}$ from the building). The measurements of the floor vibrations were carried out on the second (ground floor was unavailable) and the fourth (top) floor of the building. For both of these sources of vibrations, the horizontal component had no significant effect 
on people as opposed to the vertical vibration of the floor. The results of analyses of the influence of vertical vibration on people measured on the second floor and on the fourth floor of the building I-10 are shown in Figures 16 and 17 for the passage of the underground train and tram respectively. In the case of vibrations induced by train in underground tunnel (Figure 16), the maximum RMS value of the acceleration on the second floor of the building exceeds the threshold of human perception, while on the fourth floor they are already below this threshold. In the case of vibrations caused by tramway (Figure 17) it is exactly opposite: the maximum RMS value of the acceleration on the second floor do not exceed the human perception threshold, and on the fourth floor it is already above this threshold. It is interesting that the people from the lower and upper floors who complained about feeling vibrations, in general had no awareness of what source of vibrations was disturbing them. They demanded a reduction of the level of vibrations generated by the underground and just after the implementation of this idea it turned out that the problem was solved for those who lived on the lower floors (first and second), while the others (on the higher floors) were still exposed to the adverse influence of vibrations generated by trams.

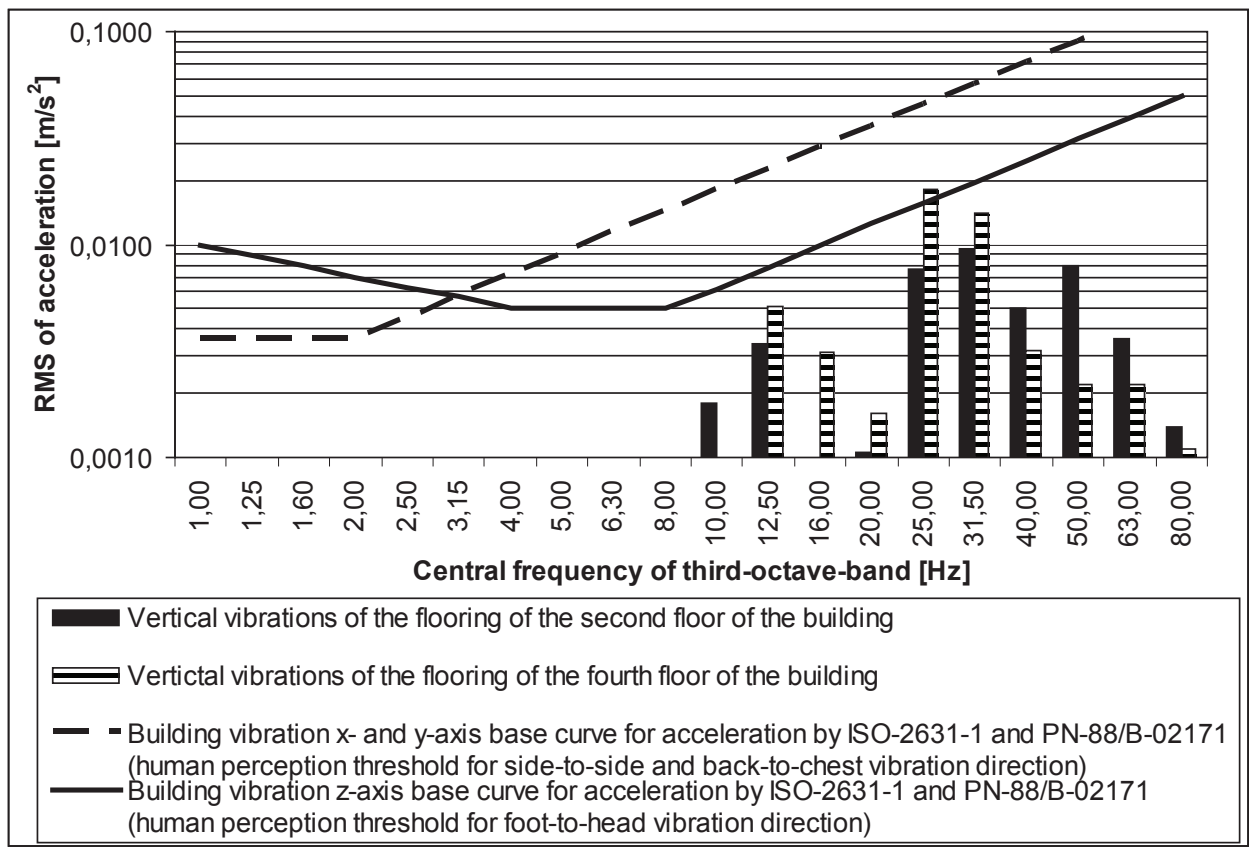

Fig. 17. Results of analyzes of the influence of vertical vibration on people living on the second and the fourth floor of the building I-10 in the case of vibrations caused by tramway passage 9 meters from the building 


\section{Conclusions}

The current state of knowledge of the propagation of transport vibrations in the ground and their reception by buildings, is based on the study of vibrations induced by operation of the surface transportation. In 2001, in the monograph [1] the author for the first time attracted the attention to the specific nature of these phenomena in the course of the vibrations generated by trains in underground tunnels. As it follows from the results of the presented experimental investigation, significant qualitative differences in the propagation of these vibrations in the ground and in the response of the building structure to these vibrations occur in the case of vibrations caused by train passages in the underground tunnel. These differences should be taken into consideration in the whole diagnostic process: from programming and execution of vibration measurement (e.g. defining in which points the measurement is necessary and representative), through calculation of the dynamic forces, up to the evaluation of influence of vibrations on the structure of buildings and the residents (sometimes also on some sensitive equipment in buildings). They also play significant role in the forecast of dynamic influences of new underground lines on the surrounding buildings, and in the forecast of dynamic influences of vibrations due to underground (from the existing tunnel) on buildings designed near the tunnels.

\section{REFERENCES}

1. K. StypuŁa, Drgania mechaniczne wywołane eksploatacja metra plytkiego i ich wplyw na budynki (Mechanical vibrations caused by shallow underground operation and their influence on buildings), Zeszyty Naukowe Politechniki Krakowskiej, seria inżynieria lądowa nr 72, Kraków (2001). [in Polish]

2. R. Ciesielski and K. StypuŁa, „Influence of shape change of carriage wheels in consequence of exploitation wear on the level of building vibration caused by shallow underground train passages - case history", Proc. Conference Structural Dynamics EURODYN 2002, Grundmann \& Schuëller (eds.) (C) 2002 Swets \& Zeitlinger, Lisse, 313-316 (2002). [in Polish]

3. D.D. Barkan, Dynamics of bases and foundations, Mc Grow-Hill Book Company, New York, San Francisco, Toronto, London (1962)

4. T.G. Gutowski, And C.L. Dym, C.L., Propagation of ground vibration: a review. Journal of Sound and Vibration: vol. 49(2), 179-193 (1976).

5. R. Ciesielski and E. Maciąg, Drgania drogowe $i$ ich wptyw na budynki,(,, Road vibrations and their influence on buildings") Wydawnictwa Komunikacji i Łączności, Warszawa (1990). [in Polish]

6. I. Czernobaj and A. Szatkowskis, Issledowanije koliebanij tonnielnych obdiełok i powierchnosti grunta pri stacionarnom wozbużdienii łotka tonniela, Mietrostroj 6/1987, 15-17 (1987). [in Russian]

7. ISO 2631-2, Guide to the evaluation of human exposure to whole body vibration. Part 2-Vibration in buildings, 2003, International Organization for Standardization.

8. PN-88/B-02171, Evaluation of vibrations influence on people in buildings, 1988, Polish Standard [in Polish]. 